\title{
EFFECT OF USING ZOOBY PROPHY CUP VERSUS TRADITIONAL PROPHY CUP ON CHILD ANXIETY
}

\author{
Thamer Alkhadra*
}

\begin{abstract}
Aim: The present study compared the new prophy cup $\left(\right.$ Zooby $\left.{ }^{\mathrm{TM}}\right)$ versus traditional prophy cup on child anxiety.

Materials and Methods: One hundred children aged 4 to 8 years (49 males and 51 females) were included in the study. The children were divided into two groups $(n=50)$. Group I: The teeth were polished with traditional prophy cup and splatter free prophylaxis paste and group II: The teeth were polished with the new Zooby ${ }^{\mathrm{TM}}$ prophy cup and splatter free prophylaxis paste. In each group, the children were further divided according to the age and sex: children less than 6 years and children above 6 years. The children were presented with the facial image scale before and after the prophylaxis treatment to point the faces they most feel like at that moment. The data collected were analyzed using independent and paired sample test.
\end{abstract}

Results: In the male group, children were more satisfied with the use of the Zooby ${ }^{\mathrm{TM}}$ cup (mean $=1.25$ ) compared to the traditional prophy cup (mean =1.96) pointing facial image scale 1 and 2. Similarly, the females also showed the same results with the Zooby ${ }^{\mathrm{TM}}$ prophy cup (mean=1.35) compared to traditional prophy cup (mean $=1.64$ ). The analyzed results according to the age demonstrated that majority of the children were happy with the use of ZoobyTM prophy cup compared to the traditional prophy cup (mean $=1.25$ and 1.33 respectively).

Conclusion: The present study concluded that the level of anxiety in children was less when Zooby ${ }^{\mathrm{TM}}$ prohy cup was used compared to the traditional prohy cup.

KEYWORDS: Prophy cup, Dental anxiety, Behavior management, Facial image scale.

\section{INTRODUCTION}

Dental anxiety is a worldwide problem and a hindrance to oral health care services among the children. This necessitates the need to manage dental anxiety in children ${ }^{(1)}$. The anxiety can deteriorate the dental health of the child exposing them to invasive dental procedures at a later stage, which may be unpleasant and further reinforce fears for dental procedures. Furthermore, the anxiety may continue into adulthood and some of these children could grow up to become parents with dental anxiety, which they pass on to their children ${ }^{(2)}$.

*Associate Professor, Department of Pediatric Dentistry and Orthodontics, College of Dentistry, King Saud University. 
In managing the dental anxiety of children, the dental procedures should be aimed at avoiding unpleasant and unproductive confrontations and to create an acceptable environment that would protect the self esteem of the child and to foster a positive attitude towards oral care for the child ${ }^{(3)}$. There are numerous techniques used for managing anxiety in a child. Some techniques are directed at preventing the development of dental anxiety, while some techniques are directed towards the treatment ${ }^{(2)}$. The prevention of dental anxiety development in children often uses the psychological management techniques, which are aimed at enhancing trust, feeling of control and the development of coping skills in children ${ }^{(4)}$. This starts from the very first contact the child makes with the dental environment which should aim at relaxing and promoting easy interaction between the child and the dental team ${ }^{(5)}$.

Other management techniques include the use of audiovisual products. This technique exposes the child to tape-slide scenes before the first dental examination with the product explaining about the first dental visit so that the child may not view the appointment and dental team as a serious threat ${ }^{(4)}$. In reducing anxiety of the child, approximately $20 \%$ of chair time could be saved ${ }^{(6)}$.

It is very important to understand the anxiety level before treatment and the factors responsible for it which will allow the dentist in applying better anxiety management techniques. Also, measurement of dental anxiety in children is important for high quality clinical care and also for research studies (7). The measurement of anxiety is usually done by direct measurement such as scales because they give data that are suitable for statistical analysis. Indirect measures mostly rely on observations and reactions of the child by others. The techniques that rely on some form of verbal-cognitive self-report (e.g., questionnaires) can be problematic because questioning the child about anxiety has limitations due to intellectual ability and comprehension ${ }^{(8)}$. The ideal measure should be valid allowing for limited cognitive and linguistic skills and be easy to use and score in clinical settings. So in such a situation, a picture scale would become a choice of anxiety measurement ${ }^{(8)}$. This involves a visual analogue scale with a very happy face indicating no pain at one end and a very unhappy face indicating severe pain at the other end ${ }^{(9)}$.

The "Tell-Show-Do" technique developed by Addelston in $1959^{(10,11)}$ is one of the oldest technique being followed to overcome child anxiety. It involves explaining and showing the child of a particular procedure and equipment before the actual procedure. For example, running a prophy cup on operator's thumb nail would be a 'do' type of activity as a method to reduce the child anxiety ${ }^{(9)}$.

Recently, a new prophy cup is available in the market which is called Zooby ${ }^{\mathrm{TM}}$ prophy angle (Zooby $^{\mathrm{TM}}$, Denticator, MO, USA) which is a soft-web, latex-free cup. The prophy cup has a disposable tip designed with an animal character that would make it attractive for children and render them easy for undergoing treatment. So the aim of the present study was to compare the new prophy cup (Zooby ${ }^{\mathrm{TM}}$ ) versus the traditional prophy cup on child anxiety.

\section{MATERIALS AND METHOD}

\section{Ethical approval:}

The study protocol was registered and approved by ethical committee at College of Dentistry Research Centre (CDRC), King Saud University (IR 0084).

\section{Study groups:}

A convenient sample of one hundred children aged 4 to 8 years old and their parents/guardians were approached in the waiting area of the Department of the Pediatric Dentistry Clinic at College of Dentistry, King Saud University. The consent of the parent or guardian to include their child in the study 
was sought. The procedure of the treatment and the survey was explained to the parents/guardian of the child and were asked to sign the informed consent form prior to their participation in the study. Among the participants, forty-nine children were males and fifty one children were females. Any children with fever, mental disorders and not willing to provide informed consent was not included in the study. The children were divided into two groups of fifty children each according to the prophy cup used. The mean age of the sample was 6 years of age. A single operator carried out all the prophylaxis procedure to avoid any influence of operator on the scoring.

Group I: The teeth were polished with traditional prophy cup (Dentsply sirona, PA, USA) and splatter free prophylaxis paste (Nupro Prophy Paste, Dentsply sirona, PA, USA)

Group II: The teeth were polished with the new Zooby ${ }^{\mathrm{TM}}$ prophy cup (Zooby ${ }^{\mathrm{TM}}$, Denticator, MO, USA) and splatter free prophylaxis paste (Nupro Prophy Paste, Dentsply sirona, PA, USA) (Figure 1 and Figure 2).

In each group, the children were further classified according to the sex and age: children less than 6 years old and children above 6 years. The children were presented with the facial image scale (Figure 3 ) before and after the prophylaxis to evaluate the children's dental anxiety and were asked to point which of the faces they most feel like at that moment. The Facial image scale adapted from Buchanan and Niven ${ }^{(9)}$, was used to evaluate the children's dental anxiety according to self-reports. This scale has a fixed number of faces for the children to choose in a row of five faces, ranging from "very happy" to "very unhappy." The faces are scored by giving a value of 1 to the happiest face and 5 to the saddest face. The scores were recorded and analyzed as $0=$ no anxiety (score 1), $1=$ low anxiety (score 2 ), 2 = moderate anxiety (score 3 ), $3=$ high anxiety (scores 4 ) and $4=$ very high anxiety (score 5). All the evaluations were conducted outside the treatment area to prevent any undue effect of treatment area on the scoring. Facial image scale makes it easier to score and understandable for a child.

The data collected were entered to a computer and analyzed using statistical package for Social Sciences (SPSS) v 16.0 program for Windows (SPSS Inc., Chicago, Illinois, USA). Independent sample and paired sample t- test were used for data analysis.

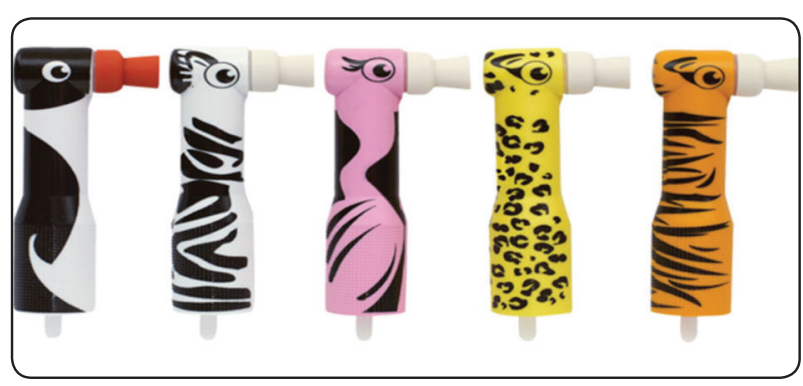

Fig. (1) Zooby ${ }^{\mathrm{TM}}$ disposable prophy angle

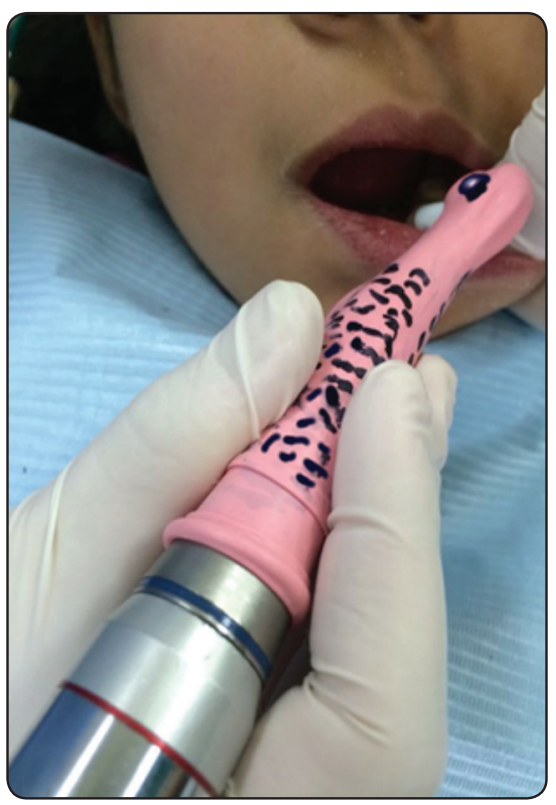

Fig. (2) Zooby ${ }^{\mathrm{TM}}$ prophy angle being used for prophylaxis.

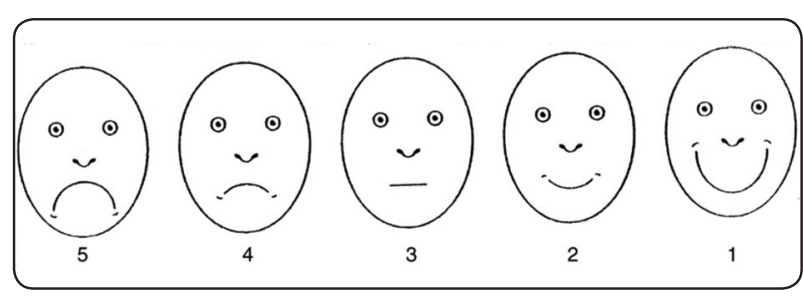

Fig. (3) Facial Image Scale 


\section{RESULTS}

All the 100 children participants included in the study responded well to the facial image scale presented before and after undergoing prophylaxis procedure thus giving a $100 \%$ response rate. Before and after the prophylaxis treatment, the children were shown the facial image scale. After prophylaxis procedure, the male group indicated that they were happy using the Zooby ${ }^{\mathrm{TM}}$ prophy cup (mean $=1.25$ ) than the traditional prophy cup (mean $=1.96)$ pointing facial image scale 1 and 2 . Similarly, the females also showed the same results that they were more happy using Zooby ${ }^{\mathrm{TM}}$ prophy cup (mean=1.35) compared to the traditional prophy cup (1.64) (Table 1).
Table 2 presents the comparison between the two prophy cups used among the male and female children. Significant difference was observed among the male and female children with the use of traditional prophy cup where as no significant difference was observed between the male and female children when Zooby ${ }^{\mathrm{TM}}$ prophy cup was used. The analyzed results to compare the children according to the age demonstrated that majority of the children aged less than 6 years were very happy with the use of Zooby ${ }^{\mathrm{TM}}$ prophy cup for prophylaxis treatment compared to the children aged 6 years and above. The pre treatment to post treatment scoring was significant in children less than 6 years and non significant in children above 6 years. (Table 3 ).

TABLE (1) Mean and SD of the anxiety scores according to gender

\begin{tabular}{|c|c|c|c|c|c|}
\hline \multirow{2}{*}{ Gender } & Group & N & Mean & SD & 'P' value \\
\hline \multirow{2}{*}{ Male } & Group I Traditional & 25 & 1.96 & 1.07 & $0.041^{*}$ \\
\cline { 2 - 5 } & Group II Zooby ${ }^{\mathrm{TM}}$ & 24 & 1.25 & 0.44 & \multirow{2}{*}{$0.039^{*}$} \\
\hline \multirow{2}{*}{ Female } & Group I Traditional & 25 & 1.64 & 1.03 & \\
\cline { 2 - 5 } & Group II Zooby & 26 & 1.35 & 0.56 & \\
\hline
\end{tabular}

*indicates statistically significant values $(p<0.05)$

TABLE (2) Mean and SD of the anxiety scores according to prophy cup used

\begin{tabular}{c|c|c|c|c|c}
\hline \multirow{2}{*}{ Gender } & Group & $\mathbf{N}$ & Mean & SD & 'P' value \\
\hline \multirow{2}{*}{$\begin{array}{c}\text { Group I } \\
\text { Traditional }\end{array}$} & Male & 25 & 1.96 & 1.07 & $0.035^{*}$ \\
\cline { 2 - 5 } & Female & 25 & 1.64 & 1.03 & 0.44 \\
\multirow{2}{*}{$\begin{array}{c}\text { Group II } \\
\text { Zooby }\end{array}$} & Male & 24 & 1.25 & 0.079 \\
\cline { 2 - 5 }
\end{tabular}

*indicates statistically significant values $(p<0.05)$ 
TABLE (3) Mean and standard deviation of the anxiety scores according to age

\begin{tabular}{|c|c|c|c|c|c|c|}
\hline Group & Age & & $\mathbf{N}$ & Mean & SD & 'P' value \\
\hline \multirow{4}{*}{$\begin{array}{c}\text { Group I } \\
\text { Traditional }\end{array}$} & \multirow{2}{*}{ Less than 6 years } & Pre & 29 & 2.52 & 1.05 & \multirow{2}{*}{$0.023 *$} \\
\hline & & Post & 29 & 1.97 & 1.23 & \\
\hline & \multirow{2}{*}{6 years and above } & Pre & 21 & 2.38 & 1.02 & \multirow{2}{*}{$0.031 *$} \\
\hline & & Post & 21 & 1.57 & .87 & \\
\hline \multirow{4}{*}{$\begin{array}{l}\text { Group II } \\
\text { Zooby }^{\mathrm{TM}}\end{array}$} & \multirow{2}{*}{ Less than 6 years } & Pre & 20 & 1.70 & 1.17 & \multirow{2}{*}{$0.021 *$} \\
\hline & & Post & 20 & 1.25 & .44 & \\
\hline & \multirow{2}{*}{6 years and above } & Pre & 30 & 1.33 & .48 & \multirow{2}{*}{0.067} \\
\hline & & Post & 30 & 1.15 & .54 & \\
\hline
\end{tabular}

* indicates statistically significant values $(p \leq 0.05)$

\section{DISCUSSION}

The present study assessed the dental anxiety among children when exposed to prophylaxis using traditional prophy cup and newly introduced animal characterized Zooby ${ }^{\mathrm{TM}}$ prophy cup. Dental fear and anxiety refers to the fear and anxiety towards going to the dentist ${ }^{(12) .}$ In fact, not only children experience this, even adolescents face this major dilemma. It becomes important for a dentist to understand the multi factorial causes of anxiety in pediatric patients and their parents. Undoubtedly, assessing of dental anxiety in children should be a part of routine dental examination for delivering good oral care ${ }^{(13)}$. Children with dental anxiety are not fully cooperative during dental treatment and may experience psychological, cognitive and behavioral consequences ${ }^{(14)}$. Consequently, this can lead to negative consequences such as more complex procedures, missed or postponed appointments which can intensify anxiety for future treatment procedures ${ }^{(15)}$. Hence, anxious children experience unpleasant situations and more dental diseases compared to non anxious counterparts ${ }^{(16)}$.
Several types of behavior management tools have been widely used in studies related to child behavior in the dental clinics ${ }^{(17)}$. The present study, adopted the facial image scale developed by Buchanan and Niven to assess the children's dental anxiety ${ }^{(9)}$. Buchanan and Niven found that the use of the facial image scale in the dental clinic as a valid dental anxiety measurement tool that can be employed with young children. It is necessary to have an accurate assessment of the anxiety level of a child during dental treatment not only to determine its prevalence but also for the child to overcome the problems related to diagnosis and treatment individually ${ }^{(9)}$. When the child is affected by their first visit to the dentist, its effect may persist as they grow older and may lead to avoidance of further dental treatment. This is why it is important to make their dental experience attractive and persuasive.

The use of psychological behavior management techniques used during the dental procedures allows the dentist and child to communicate and help develop a sense of trust and achievement. The reduction in anxiety level of a child post 
treatment compared to the anxiety level before treatment is effectively achieved through the use of psychological management techniques to definitive therapy ${ }^{(18)}$. Most children especially preschool age, feel discomfort when they are seated in the dental chair ${ }^{(19)}$. An instrument to persuade a child is used by a dentist to make it attractive for them to agree to undergo the dental treatment (20).

In our study, we compared the Zooby ${ }^{\mathrm{TM}}$ prophy cup and traditional prophy cup on child anxiety. The different animal character and various colors of the Zooby ${ }^{\mathrm{TM}}$ prophy cup fascinated the child more as it entered the mouth. Previous studies have reported that gender difference affects the scoring of the anxiety level of a child ${ }^{(21)}$ where as some studies report no significant difference between males and females ${ }^{(22)}$. The study also agrees with the findings of Paryab and Hosseinbor where they concluded that children older than 6years are less anxious compared to children below 6 years of age ${ }^{(22)}$. In the present study, the male children were easily attracted by the Zooby ${ }^{\mathrm{TM}}$ prophy cup and selected the happy face after the prophylaxis procedure compared to the female children but the difference in the results was not significant which was similar to the findings of the previous study ${ }^{(22)}$.

Dental anxiety in no way should be overlooked in general or pediatric dentistry. It is of utmost importance for the dentist or pediatric dentist to develop techniques or strategies for assessing preventing and controlling dental anxiety which should aim at providing high level of oral health care for the children, adolescents and their parents. These techniques should further help in developing a more trustful and caring relationship between the child and dentist or pediatric dentists. However, the present study had some limitations such as low sample size, unequal male to female ratio and presence or absence of parents during the prophylaxis was not considered for anxiety scoring.

\section{CONCLUSION}

The present study concluded that the level of anxiety in children was less when Zooby ${ }^{\mathrm{TM}}$ prophy cup was used as compared to the traditional prohy cup.

\section{ACKNOWLEDGEMENT}

The author would like to thank Dr. Ahmed Al Quraani and Dr. Sultan Al Obaydaa for their unconditional support during the research.

\section{REFERENCES}

1. Kinirons MJ, Stewart C. Factors affecting levels of untreatedcaries in a sample of 14-15- year-old adolescents in Northern Ireland. Community Dent Oral Epidemiol 1998; 26: 7-11.

2. Folayan MO, Ufomata D, Adekoya-Sofowora CA, Otuyemi OD, Idehen E. The effect of psychological management of dental anxiety in children. J Clin Pediatr Dent $2003 ; 27: 365-370$

3. Milgrom P, Weinstein P. Dental fears in general practice: new guidelines for assessment and treatment. Int Dent $\mathrm{J}$ 1993; 43: 288-293.

4. McDonald RE. Behavior guidance in the dental office. In:McDonald RE, Dentistry for the child and adolescent. $2^{\text {nd }}$ ed., St. Louis, C.V. Mosby Company, pp. 26-37, 1974.

5. Barenie JT. Behavior modification techniques. In: Ripa LW, Barenie JT (eds). Management of dental behavior in children. 1979. Littleton Massachusetts: PSG Publishing, pp. 61-73.

6. Ayer W. Psychology and dentistry: mental health aspects of patient care. Haworth Press Inc, 2005.

7. Girdler NM, Wilson K, Hill CM. Clinical sedation in dentistry.2009. Chichester: John Wiley and Sons Ltd.,

8. Aartman IHA, Van Everdingen TA, Hoogstraten J, Schuurs AHB. Self-report measurements of dental anxiety and fear in children: a critical assessment. J Dent Child1998;65: $252-258$

9. Buchanan H, Niven N. Validation of a Facial Image Scale to assess child dental anxiety. Int J Paediatr Dent 2002; $12: 47-52$

10. Addelston HK. Child patient training. Fort Rev Dent Soc 1959; 38:7-9 and 27-29. 
11. Boj JR, Davila JA. Differences between normal and developmentallydisabled children in a first dental visit. J Dent Child 1995; 62:52-56.

12. Gao X, Hamzah SH, Yui CKY, McGrath C, King, NM. Dental fear and anxiety in children and adolescents: Qualitative study using YouTube. J Med Internet Res 2013; 15(2): e29.

13. Assuncão CM, Losso EM, Andreatini R, de Menezes JV. The relationship between dental anxiety in children, adolescents and their parents at dental environment. J Indian Soc Pedod Prev Dent 2013;31(3):175-9

14. Kritsidima M, Newton T, Asimakopoulou K. The effects of lavender scent on dental patient anxiety levels: A cluster randomised-controlled trial. Community Dent Oral Epidemiol 2010;38:83-7

15. Armfield JM, Stewart JF, Spencer AJ. The vicious cycle of dental fear: Exploring the interplay between oral health, service utilization and dental fear. BMC Oral Health 2007;7:1

16. Messl-Huber M, Freeman R, Humphris G, MacGillivray $\mathrm{S}$, Terzi N. Empirical evidence of the relationship between parental and child dental fear: A structured review and meta-analysis. Int J Paediatr Dent 2010;20:83-101.
17. Gustaffson A. Dental behavior management problems among children and adolescents - a matter of understanding? Studies on dental fear, personal characteristics and psychosocial concomitants. Swed Dent J Suppl 2010; 202(2):1-46.

18. Nakai Y, hirakawa T, Milgrom P, Coolidge T, Heima M, Mori Y, Ishihara C, Yakushiji N, Yoshida T, Shimono T. The children's fear survey schedule-dental subscale in Japan. Comm Dent Oral Epidemiol 2005; 33:196-204.

19. Woodmansey KF. The prevalence of dental anxiety in patients of a university dental clinic. J Am College Health 2005; 54(1):59-61.

20. Klingberg G, Broberg AG. Dental fear/anxiety and dental behavior management problems in children and adolescents: A review of prevalence and concomitant psychological factors. Int J Paedia Dent 2007; 17:391-406.

21. Wong HM, Humpris GM, Lee GTR. Preliminary validation and reliability of the modified child dental anxiety scale. Psychological Reports 1998; 83:1179-1186.

22. Paryab M, Hosseinbor M. Dental anxiety and behavioral problems: A study of prevalence and related factors among a group of Iranian children aged 6-12. Journal of Indian Society of Pedodontics and Preventive Dentistry 2013;31(2): 82-86 